\section{Immunohistochemical evidence of Muc1 expression during rat embryonic development}

\section{E. Lacunza, ${ }^{1}$ V. Ferretti, ${ }^{1}$ C. Barbeito, ${ }^{2}$}

A. Segal-Eiras, ${ }^{1}$ M. V. Croce ${ }^{1}$

${ }^{1}$ Centre for Basic and Applied

Immunological Research (CINIBA),

Faculty of Medical Sciences, National

University of La Plata, Argentina

${ }^{2}$ Cathedra of Histology and Embryology,

Faculty of Veterinary Sciences, National

University of La Plata, Argentina

\section{Abstract}

During embryonic development, studies on mouse and human embryos have established that Muc1/MUC1 expression coincides with the onset of epithelial sheet and glandular formation. This study aimed therefore at evaluating the temporal and spatial expression of Mucl at different stages of rat development. In this report, 80 animals were included: 64 rat foetuses at 13, 14, 15, 16, 17, 18, 19 and 20 days of gestation from pregnant females (WKAH/Hok), 8 embryos each stage. Standard immunohistochemistry was performed using anti-MUC1 cytoplasmic tail polyclonal antibody (CT33). The reaction was considered positive when more than $5 \%$ of the cells were stained; reaction patterns were: $\mathrm{L}=$ linear, membrane, $\mathrm{C}=$ cytoplasmic and $\mathrm{M}=$ mixed; nuclear staining was also recorded. Intensity was graded as negative $(-)$, low $(+)$, moderate $(++)$ and strong (+++). Mucl expression was observed with a low intensity on 13th day (13 D) in the stomach, lung and kidney; at $14 \mathrm{~d}$, small intestine and pancreas were also reactive; at $16 \mathrm{D}$, liver and esophagus and at $18 \mathrm{D}$, trachea and salivary glands. During the development, intensity increased while the pattern of expression changed: at the first days of gestation, it was predominantly linear and apical while during further development an increase in cytoplasmic expression was observed. Trachea, stomach, kidney and lung epithelia were the more reactive tissues. In specimens belonging to neonates and adults, all tissues analyzed showed similar Mucl expression. The findings of this study assess that Mucl is highly expressed in the epithelial rat embryonic development.

\section{Introduction}

Adequate cell adhesive properties are required for most developmental processes generating a multicellular organism; in particular, cell adhesion is critical to the formation of coherent sheets of cells or epithelia. ${ }^{1}$

Mucins serve as an integral structural component of epithelial tissues, which help with protection, lubrication and transport between either the external medium or lumen and the epithelial cells. Moreover, it has been proved that at least some mucins, such as MUC1, may act as adhesive as well as antiadhesive molecules. $^{2}$

Membrane-bound mucins are modular proteins; mucin 1, named MUC1 in humans and Mucl in other species, is the first transmembrane mucin described ${ }^{3,4}$ and it is normally expressed on apical mammalian epithelial tissues. ${ }^{4.9}$ Full length MUC1 is synthesized as a single polypeptide chain which undergoes an early proteolytic cleavage creating two subunits that remain associated during its posttranslational processing and transport to the cell surface. ${ }^{10}$ The large fragment contains most of the extracellular domain, including the signal sequence and a tandem repeat ${ }^{11}$ while the small subunit contains a short extracellular domain, a transmembrane domain and a cytoplasmic tail which are highly conserved across species. ${ }^{12}$

MUC1 has also been associated to diverse human carcinomas as well as to certain haematological malignancies. ${ }^{4,13-15}$ In this sense, it has been extensively studied in breast tumors, ${ }^{2,13,16,17}$ where it is upregulated with aberrant expression over the entire cell surface, which generates cell adhesion inhibition as well as increased metastatic and invasive potential of tumor cells. ${ }^{18}$ Furthermore, MUC1 cytoplasmic domain binds directly to and stabilizes $\beta$-catenin constituting a key modulator of several signalling pathways that affect motility and cell morphology. ${ }^{19}$

Studies on mouse and human embryos have established that Muc1/MUC1 expression coincides with the onset of epithelial sheet and glandular formation during embryonic development. ${ }^{20-22}$ Moreover, a possible role of MUC1 in cellular adhesion mechanisms during organogenesis has been proposed. ${ }^{21}$ Taking into account these reports and also the adherent and anti-adherent properties of Muc1/MUC1 as well as its relationship with signal transduction, it would be expected that Mucl appears early in epithelial development in mammalian species.

During morphogenesis, epithelia undergo extensive rearrangements in response to extracellular signals; these require the coordinated regulation of cell-cell adhesion, cellmatrix adhesion and the cytoskeleton. The aim of the present study was to evaluate the temporal and spatial expression of Mucl at different stages of rat development.
Correspondence: Maria Virginia Croce, Centre for Basic and Applied Immunological Research (CINIBA), Faculty of Medical Sciences, National University of La Plata, Calle 60 y 120, 1900 La Plata, Argentina.

Tel. +54.221.4236711 - Fax: +54.221 .4258989 .

E-mail: crocevir@hotmail.com

Key words: Muc1/MUC1, rat, embryonic development, immunohistochemistry.

Contributions: EZ and VF performed the techniques, evaluated them and drafted the manuscript, CB evaluated the results; AS-E and MVC proposed the objectives and design, evaluated data and critically revised the manuscript; all authors approved the version to be published.

Acknowledgements: the authors would like to thank Prof. K. Chul Kim for providing anti-MUC1 cytoplasmic tail polyclonal antibody (CT33) and Mr. Juan Carlos Molina for technical assistance. This work was supported by grants of the Comisión de Investigaciones Científicas de la Provincia de Buenos Aires (CICPBA) and the National University of La Plata (UNLP).

Received for publication: 20 July 2010. Accepted for publication: 2 November 2010.

This work is licensed under a Creative Commons Attribution 3.0 License (by-nc 3.0).

(C) Copyright E. Lacunza et al., 2010

Licensee PAGEPress, Italy

European Journal of Histochemistry 2010; 54:e49 doi:10.4081/ejh.2010.e49

\section{Materials and Methods}

\section{Animals and samples}

A total of 80 animals were included in this study: 64 rat foetuses were collected at 13,14 , $15,16,17,18,19$ and 20 days of gestation (stages 13D-20D) from pregnant females (WKAH/Hok); 8 embryos from each stage were included. Eight independent samples belonging to each embryonic day were examined and scored. Copulation was determined by the presence of a vaginal plug; the middle of the artificial night was designed as day 0 of pregnancy. ${ }^{23}$

The following organs were studied: trachea, lung, esophagus, stomach, small intestine, liver, pancreas, kidney and salivary glands.

Tissue samples from the same organs belonging to neonates (postnatal day $14 ; \mathrm{n}=8$ ) and adults $(n=8)$ were employed as positive controls.

This investigation was carried out in accordance with the Guide for the Care and Use of Laboratory Animals published by the National 
Institute of Health (NIH, USA, Publication No. 85-23, revised 1996).

\section{Tissue processing}

Embryos were obtained by laparotomy and hysterectomy of the pregnant females. The number of embryos in each gestation ranged from 4 to 12 which were processed and studied. After the extirpation of the embryonic sac, whole embryos were washed with $0.01 \mathrm{M}$ phosphate buffer saline pH 7.4 (PBS) and fixed in $10 \%$ formaldehyde solution for $3 \mathrm{~h}$. After this period of time, the embryos were washed in water, dehydrated and clarified with xylol, embedded in paraffin, and finally blocked with paraffin. The organs obtained from neonates and adults were fixed in $10 \%$ formaldehyde in PBS for $3 \mathrm{~h}$ dehydrated in ethanol, clarified and embedded and blocked with paraffin.

Sections were made with a microtome with a thickness of $6 \mu \mathrm{m}$ (foetuses) and $4 \mu \mathrm{m}$ (neonates and adults), placed in slides treated with silane (silicon tetrahydride) followed by hematoxylin and eosin staining and immunohistochemical analysis.

\section{Antibody}

A polyclonal antibody (Ab) CT33, developed in rabbit against the last 17-aminoacids (SSLSYNTPAVAATSANL) of the cytoplasmic tail of human MUC1 (MUC1CT) ${ }^{16}$ was employed.

\section{Inmunohistochemical analysis}

Immunohistochemistry was performed according to standard procedures as reported in a previous study. ${ }^{6}$ Briefly, dewaxed sections were treated with $10 \mathrm{mM}$ sodium citrate buffer at $100^{\circ} \mathrm{C}$ for $5 \mathrm{~min}$ for antigen retrieval and were placed in methanol with $0.3 \% \mathrm{H}_{2} \mathrm{O}_{2}$ to block endogenous peroxidase activity; after three washes in PBS, sections were blocked for non-specific binding with normal horse serum diluted $1: 10$ in $1 \%$ bovine serum albumin in PBS, (BSA)/PBS. Samples were then incubated overnight with the primary Ab (1 $\mu \mathrm{g} / \mathrm{mL}$; dilution $1: 100$ ) at $4^{\circ} \mathrm{C}$, whereas negative controls were incubated with PBS under the same conditions. After incubation with secondary peroxidase labeled anti-rabbit Ig (1:150; Dako, Glostrup, Denmark), reaction was developed with 3-3'-diaminobencidine and $0.03 \% \mathrm{H}_{2} \mathrm{O}_{2}$ in PBS. Visualization of immunostaining was achieved using diaminobenzidine (Sigma, St. Louis, MO, USA) as substrate. Finally, sections were counterstained with hematoxylin (Sigma), dehydrated and coverslipped with mounting media. Samples were evaluated under light microscope and the reaction was considered positive when more than $5 \%$ of the cells were stained. The patterns of reaction were: $\mathrm{L}=$ lin-
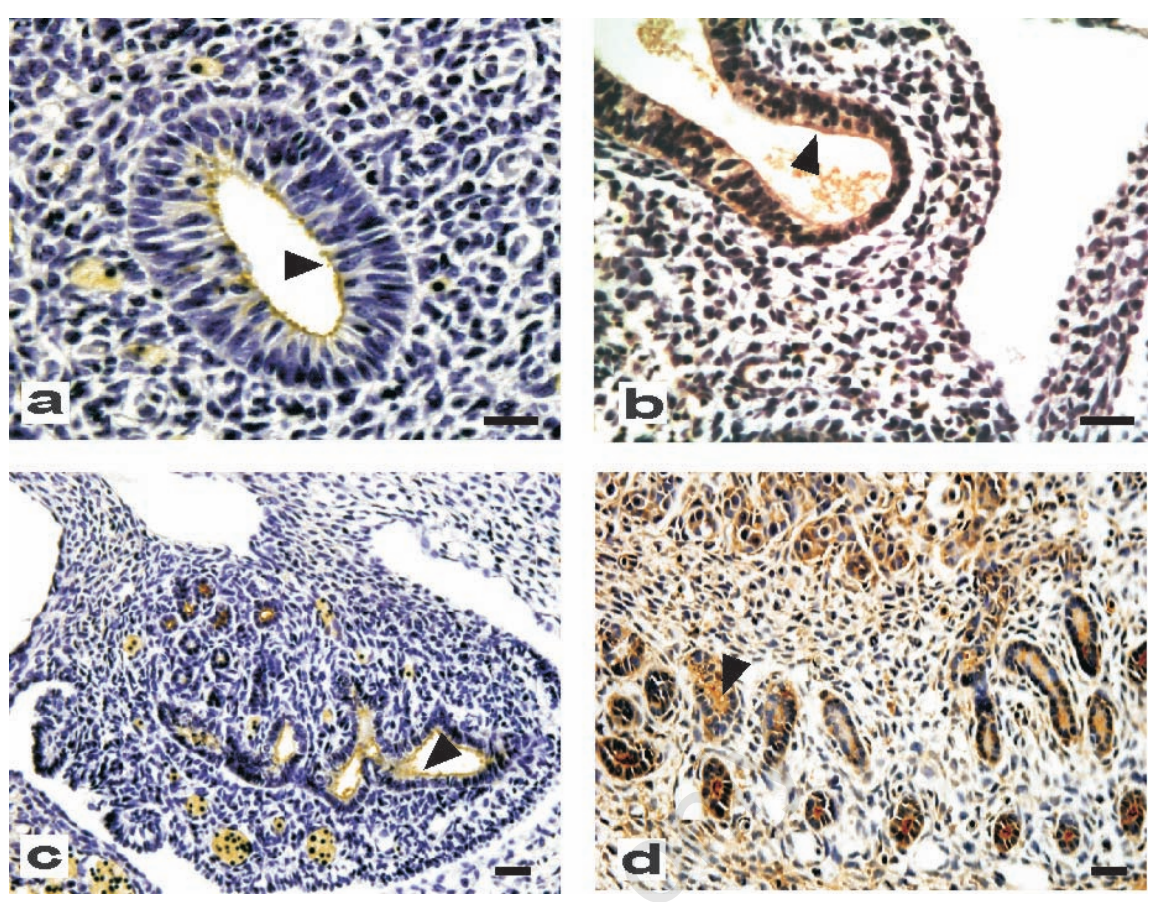

Figure 1. Immunohistochemical staining of Muc1 in different rat embryonic tissues of 13 and 14 days of gestation detected with anti-MUC1CT CT33Ab. Muc1 is located at the apical borders of developing epithelial sheets in the different organs (arrows). Stomach from foetus of $13(\mathrm{a}, 40 \mathrm{x})$, primordial lung buds from fetus of 13 days of gestation $(\mathrm{b}, 40 \mathrm{x})$ and nephric tubules of developing kidney from fetuses of 13 (c, 10x) and 14 (d, 10x). Scale bar $=20 \mu \mathrm{m}(\mathrm{a}, \mathrm{b}) ; 50 \mu \mathrm{m}(\mathrm{c}, \mathrm{d})$.
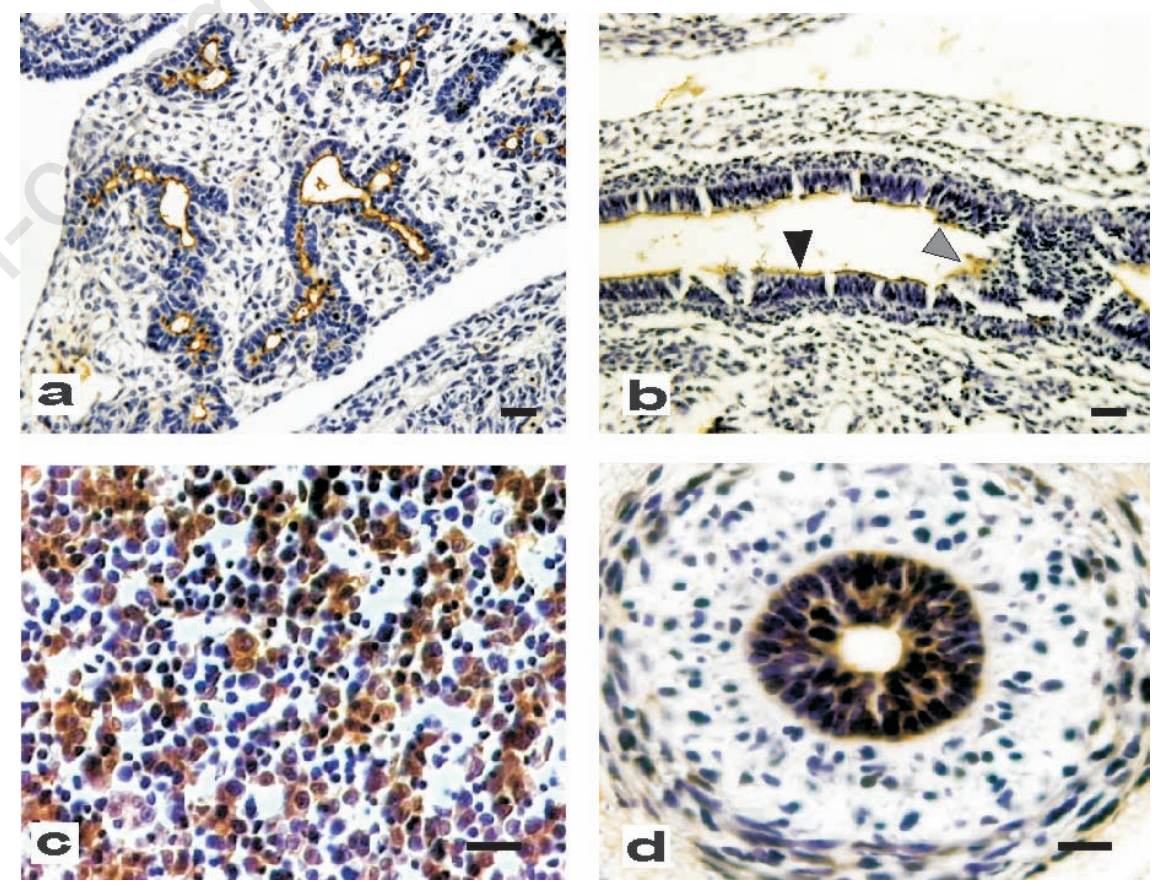

Figure 2. Immunohistochemical staining of MUC1 in different embryonic tissues of 15 and 16 days of gestation of rat detected with CT33Ab. Pancreas of 15 (a, 10x), small intestine of $15(\mathrm{~b}, 10 \mathrm{x})$, liver of $16(\mathrm{c}, 40 \mathrm{x})$, and esophagus from fetus of 16 days of gestation $(\mathrm{d}, 40 \mathrm{x})$. Black arrow indicates positive reaction; grey arrow indicates epithelial proliferation with lumen obstruction. Scale bar $=20 \mu \mathrm{m}(c, d) ; 50 \mu \mathrm{m}(\mathrm{a}, \mathrm{b})$. 
ear membrane, $\mathrm{C}=$ cytoplasmic and $\mathrm{M}=$ mixed, linear and cytoplasmic; apical and non-apical staining was also recorded as well as nuclear reactivity. Staining intensity was scored in a semiquantitative manner and was graded as negative $(-)$, low $(+)$, moderate $(++)$ and strong $(+++)$.

\section{Results}

Inmunohistochemical results are summarized in Table 1. In most cases, mucin 1 expression was detected before cytodifferentiation. The pattern of reaction was predominantly linear, in the apical part of the epithelial cells (Figures 1, 2, 3, 4).

\section{Day \#13}

Mucl protein was observed in stomach, lung and kidney with either low or moderate reaction intensity; in stomach, staining was restricted to the epithelial surface (Figure 1a). At the epithelial tubules originated from the primordial lung buds, reactions were heterogeneous since some samples showed a mixed pattern (Figure 1b) while a linear and apical staining was also found; nephric tubules of the developing kidney showed an apical and linear reaction (Figure 1c). In these two organs, lumen contents also showed immunoreactivity.

\section{Day \#14}

Mucl expression was found in small intestine epithelial cells and pancreas with a reaction that varied from moderate to intense (data not shown); in the pancreas, acini were not completely developed although tubules of epithelial cells were detectable showing a high expression of Mucl. In lung, kidney (Figure 1d) and stomach, the intensity of the reaction was more intense compared with day \#13.
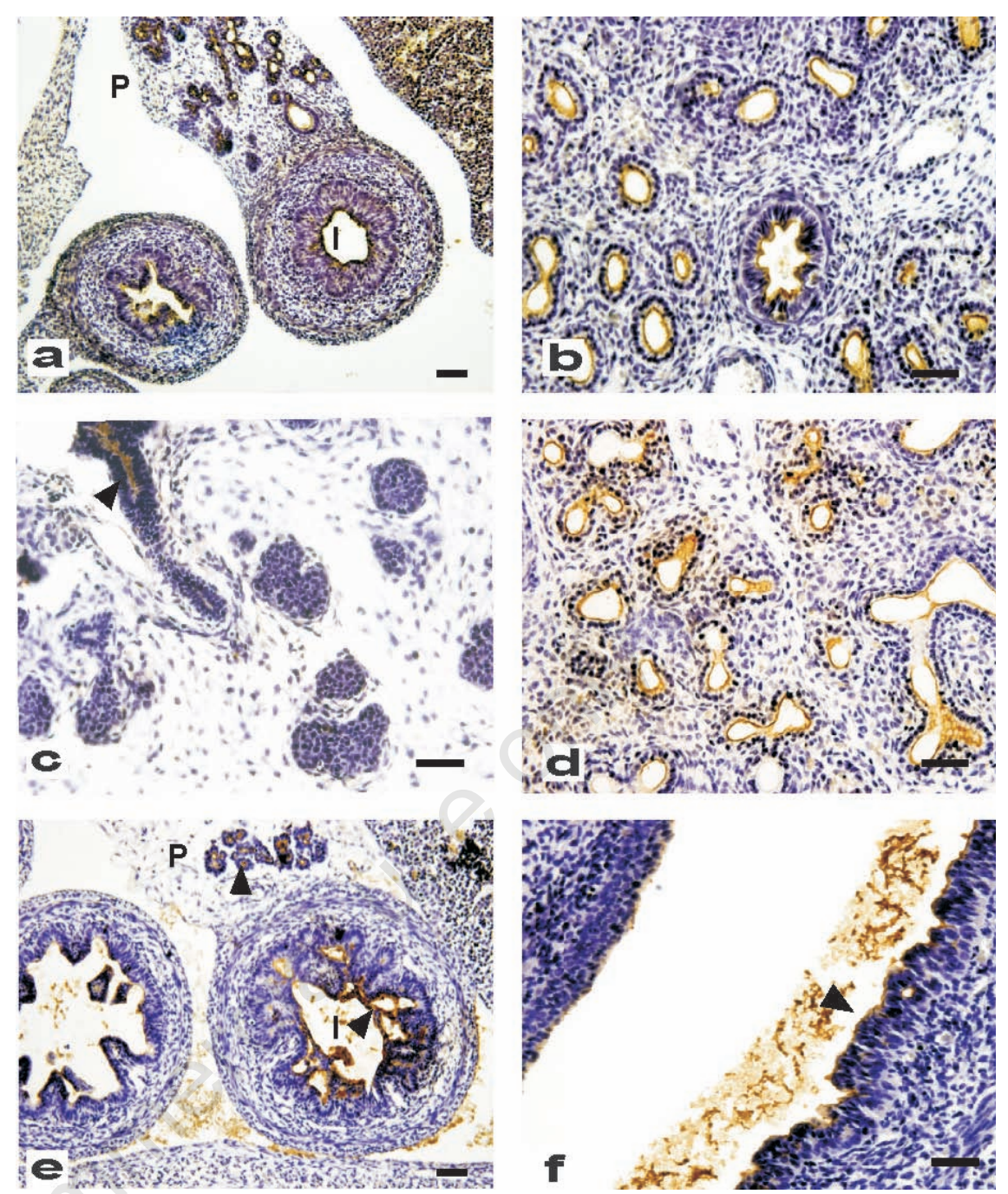

Figure 3. Immunohistochemical staining of MUC1 in different embryonic tissues of 17 and 18 days of gestation of rat detected with CT33Ab; pancreas and small intestine of 17 (a, 10x) and $18(e, 10 x)$; lung of $17(b, 40 x)$ and $18(d, 40 x)$; salivary glands of $18(c, 40 x)$ and stomach of 18 days of gestation $(f, 40 x)$. P, pancreas; I, small intestine. Black arrows indicate positive reaction. Scale bar $=20 \mu \mathrm{m}(\mathrm{b}, \mathrm{c}, \mathrm{d}, \mathrm{f}) ; 50 \mu \mathrm{m}(\mathrm{a}, \mathrm{e})$.

Table1. Inmunohistochemical results of Muc1 expression in different tissues from rat embryos, neonates and adults. The intensity of reaction was scored as absent $(-)$, low $(+)$, moderate $(++)$ and strong $(+++)$.

\begin{tabular}{|c|c|c|c|c|c|c|c|c|c|c|}
\hline & \multicolumn{8}{|c|}{ Fetuses gestional days } & \multirow{2}{*}{$\begin{array}{c}\text { Neonates } \\
2 \text { weeks }\end{array}$} & \multirow{2}{*}{$\begin{array}{c}\text { Adults } \\
\text { 10-12 weeks }\end{array}$} \\
\hline & 13 & 14 & 15 & 16 & 17 & 18 & 19 & 20 & & \\
\hline \multicolumn{11}{|l|}{ Tissues } \\
\hline Esophagus & - & - & - & $+(\mathrm{M})$ & $+(\mathrm{M})$ & $+(\mathrm{M})$ & $++(\mathrm{M})$ & $++(\mathrm{M})$ & $++(\mathrm{M})$ & $++(\mathrm{M})$ \\
\hline Stom ach & $+(\mathrm{L})$ & $++(\mathrm{L})$ & $++(\mathrm{L})$ & $++(\mathrm{L} / \mathrm{M})$ & $+++(\mathrm{L} / \mathrm{M})$ & $+++(\mathrm{L} / \mathrm{M})$ & $+++(\mathrm{M})$ & $+++(\mathrm{M})$ & $+++(\mathrm{M})$ & $+++(\mathrm{M})$ \\
\hline Sm all intestine & - & $++(\mathrm{L})$ & $++(\mathrm{L})$ & $++(\mathrm{L} / \mathrm{M})$ & $++(\mathrm{L} / \mathrm{M})$ & $++(\mathrm{L})$ & $+++(\mathrm{L} / \mathrm{M})$ & $+++(\mathrm{M})$ & $+++(\mathrm{M})$ & $+++(\mathrm{M})$ \\
\hline Pancreas & - & $+++(\mathrm{L})$ & $+++(\mathrm{L})$ & $+++(\mathrm{L})$ & $+++(\mathrm{L} / \mathrm{M})$ & $+++(\mathrm{L})$ & $+++(\mathrm{L} / \mathrm{M})$ & $+++(\mathrm{M})$ & $+++(\mathrm{M})$ & $+++(\mathrm{M})$ \\
\hline Liver & - & - & - & $++(C)$ & $++(\mathrm{C})$ & $++(\mathrm{C})$ & $++(\mathrm{C})$ & $++(\mathrm{C})$ & $++(\mathrm{C})$ & $++(\mathrm{C})$ \\
\hline Salivary glands & & & & & & $++(\mathrm{L})$ & $++(\mathrm{L})$ & $++(\mathrm{L})$ & $++(\mathrm{L})$ & $++(\mathrm{L})$ \\
\hline Trachea & - & - & - & - & - & $++(\mathrm{L})$ & $++(\mathrm{L})$ & $++(\mathrm{L})$ & $++(\mathrm{L})$ & $++(\mathrm{L})$ \\
\hline Lung & $+(\mathrm{L} / \mathrm{M})$ & $++(\mathrm{L})$ & $++(\mathrm{L})$ & $+++(\mathrm{L} / \mathrm{M})$ & $+++(\mathrm{L})$ & $+++(\mathrm{L})$ & $+++(\mathrm{L})$ & $+++(\mathrm{L})$ & $+++(\mathrm{L})$ & $+++(\mathrm{L})$ \\
\hline Kidney & $+(\mathrm{L})$ & $++(\mathrm{L})$ & $++(\mathrm{L})$ & $++(\mathrm{L})$ & $+++(\mathrm{L} / \mathrm{M})$ & $+++(\mathrm{L} / \mathrm{M})$ & $+++(\mathrm{L} / \mathrm{M})$ & $+++(\mathrm{L} / \mathrm{M})$ & $+++(\mathrm{L} / \mathrm{M})$ & $+++(\mathrm{L} / \mathrm{M})$ \\
\hline
\end{tabular}

4 Mixed pattern. 


\section{Day \#15}

At this stage, all reactive tissues showed a strong staining. In the pancreas, at the apical membranes in the luminal areas of developing tubules, Muc1 was positive with a linear pattern (Figure 2a). In small intestine, an increased intensity was coincident with the appearance of columnar cells replacing cuboidal cells (Figure 2b).

\section{Day \#16}

A cytoplasmic reaction was observed in the hepatic cords of embryonic liver with a low intensity (Figure 2c). On the other hand, esophagus showed a low to moderate reaction with an apical pattern (Figure 2d). At this stage, the lumen of the pancreatic epithelial tubules became narrower, maintaining Mucl expression at the luminal surface of the epithelial cells. A strong reaction was observed in kidney, lung and stomach.

\section{Day \#17}

All tissues mentioned above reacted positively with a strong intensity. In the pancreas, secretory acini were present and they showed Mucl expression with a mixed pattern of reaction (Figure 3a). On this day, the epithelium of the stomach begins to grow in depth to form the gastric glands and Mucl expression was observed at the epithelial cells. Similarly, bronchi and bronchiolar epithelial cells as well as pulmonary alveoli are developed at this stage, with Mucl expression restricted to the luminal cells of bronchi and bronchioli (Figure $3 \mathrm{~b}$ ).

\section{Day \#18}

The trachea showed Mucl expression on this day (data not shown). Mucl reaction covered the entire luminal epithelia with a well defined linear pattern; a positive staining was also observed in lumen secretions. On this gestational day, Mucl expression in salivary glands was also observed; excretory ducts were stained with a mixed pattern and a moderate to strong intensity while acini did not show any reaction (Figure $3 \mathrm{c}$ ). On the other hand, bronchi and bronchioli showed an increased Mucl expression respect to day \#17; the reaction was found at epithelial cells with a mixed pattern while bronchial lumen secretion was also reactive (Figure $3 \mathrm{~d}$ ).

The small intestine showed a positive reaction with a strong intensity (Figure $3 \mathrm{e}$ ). In the stomach, the mucosa begins to differentiate in squamous cell epithelium and glandular epithelium; both showed a moderate to strong reaction (Figure $3 \mathrm{f}$ ).

\section{Day \#19}

Compared with the previous day, in the
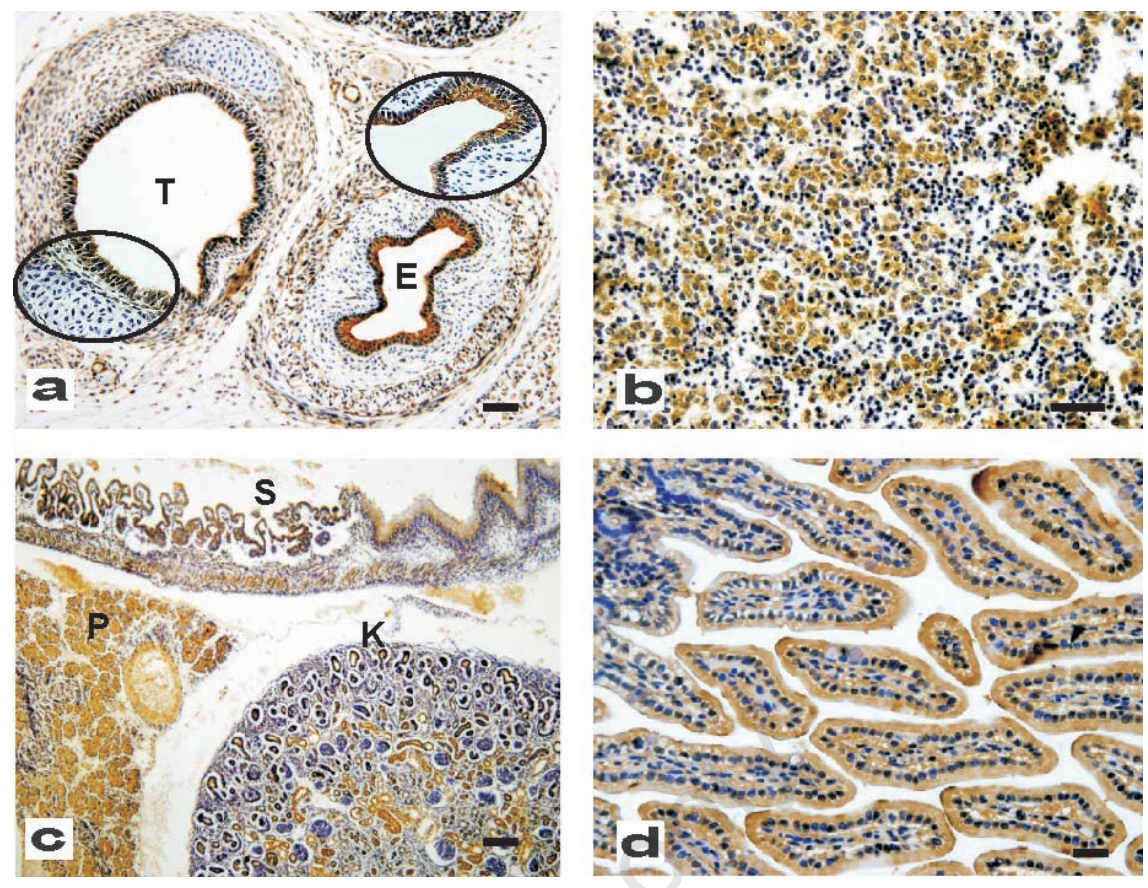

Figure 4. Immunohistochemical staining of MUC1 in different embryonic tissues of 19, 20 days of gestation and neonates of rat detected with CT33Ab; trachea and esophagus of 19 days of development $(\mathrm{a}, 10 \mathrm{x}, 40 \mathrm{x})$, liver of 19 (b, 40x), kidney, esophagus and pancreas of 20 days of gestation $(c, 10 x)$ and small intestine of neonate $(d, 40 x)$. S, stomach; $P$, pancreas; K, kidney; T, trachea; E, esophagus. Scale bar $=20 \mu \mathrm{m}(\mathrm{a}, \mathrm{b}) ; 50 \mu \mathrm{m}(\mathrm{c}, \mathrm{d})$.

stratified epithelium of the esophagus and trachea, a more intense Mucl reaction was observed (Figure 4a).

In addition, stomach, lung, kidney and small intestine were well identified and, as it was previously described, they expressed Mucl protein while the liver showed a higher percentage of Mucl reaction respect to previous gestational days (Figure 4b).

\section{Day \#20}

At this stage, mucous and serous acini from salivary glands were early found and Mucl expression was positive; in the stomach, this mucin was observed in the apical part of the epithelial cells of the glandular region and a moderate reaction was also found in the apical part of the non-glandular region (Figure 4c). In the pancreas, a strong reaction was observed; however, the pattern of expression changed being predominantly mixed instead of linear (Figure 4c). Finally, the kidney showed Mucl expression in the epithelial cells at the well differentiated collecting ducts and nephric tubules (Figure 3c).

\section{Neonates and adults}

All tissues previously analyzed showed Muc1 expression with a moderate to strong intensity without significant changes (Figure 4d).

\section{Discussion}

Cellular differentiation to a specific adult tissue results from selective genetic expression at a precise moment with a determined pattern. Human MUC1 mucin interest has been mainly focused on its role in carcinogenesis and tumor progression in different malignancies; in contrast, its role in human and non-human embryogenesis remains unclear. For this reason, we studied Mucl expression in rat embryonic development using immunohistochemistry with an anti-human MUC1CT antibody, which is directed against the wellconserved cytoplasmic domain of MUC1. ${ }^{16}$

It is well known that MUC1 has been mainly studied in breast cancer and also in benign breast diseases and normal human mammary epithelia. ${ }^{4,724,25}$ In fact, MUC1 was the first mucin to be cloned, initially from mammary carcinomas ${ }^{26}$ and subsequently from other tissues. ${ }^{27}$ Considering that this research was developed in order to study Mucl expression from the first stages of rat embryonic development up to birth, we included organs that express Mucl in adults and that may be identified during the developmental process. During this period, the rat mammary gland is difficult to identify ${ }^{28}$ and, consequently, it was excluded from this study. 
Our data demonstrated that rat Mucl is expressed in several embryonic epithelial tissues, being stomach, lung and kidney the first to show reactivity (13D). In these tissues, Mucl expression was mainly restricted to the apical part of the epithelial cells, in coincidence with the characteristic pattern of Mucl in adult rat epithelial tissues. ${ }^{9}$

In consequence, it may be suggested an important role of Mucl from early development in these organs.

At 14D, Mucl expression was found in the epithelial cells of small intestine and pancreas, with a reaction that varied from moderate to intense.

Although development of the human small intestine between the sixth and eighth weeks (equivalent to 14D to 16D in rats) has been controversial, studies in rats demonstrated that small intestine underwent intense epithelial proliferation without complete lumen obstruction. At 14D, duodenum lumen spaces are enlarged without apparent occlusion while at $15 \mathrm{D}$ proliferative cells are evident in the lumen. ${ }^{29}$ In coincidence, our results showed that at 14D, Mucl expression was restricted to the epithelial sheet while at 15D, we found that Mucl was also reactive in proliferative cells. These observations would indicate that Muc1 might be associated with proliferation.

The rat pancreatic development in uterus could be divided into four representative stages as follows: i) initial epithelial buds (12D); ii) elongated and branching epithelium (13D-14D); iii) tubular structure (15D-16D) and iv) acinar structure (from 17D).$^{30}$ Our results clearly showed Mucl expression at 14D, which coincides with epithelia pancreatic differentiation. Furthermore, the reaction increased in the following days, when the lumen of the pancreatic epithelial tubules became narrower and the secretory acini were evident (15D-17D). This is in agreement with mouse embryonic development, since Braga et $a l .{ }^{20}$ found that the expression of Mucl coincided with the onset of epithelial sheet and glandular formation.

At $16 \mathrm{D}$, a cytoplasmic reaction was observed in the hepatic cords of embryonic liver, with a low to moderate intensity. Interestingly, at this stage hepatoblasts are in an actively migrating period. $^{31,32}$ On the other hand, the expression fell and disappeared in neonates and adults, respectively. These results are interesting since in humans, MUC1 expression is very low or absent in adult normal liver while is highly expressed during hepatocarcinogenesis ${ }^{33}$ in coincidence with cellular division. Tacking into account that mature hepatocytes have an enormous proliferative potential, ${ }^{34,35}$ it would be interesting to study Muc1/MUC1 expression during liver regeneration.

Esophagus also showed Mucl expression on
16D. At this stage, the epithelium consists on 3-4 cellular layers, whereas the differentiation starts after 17D; therefore, it is not surprising that Muc1 was observed before this event.

Regarding salivary glands, at $14 \mathrm{D}$, their rudiments arise as a down growth of the oral epithelium into the underlying mesenchyme as solid cords of cells. ${ }^{36}$ Branching morphogenesis is advanced before the first structural signs of cellular differentiation become apparent within the early secretory cells; $;^{36}$ this process occurs at $16 \mathrm{D}$, which also coincides with our findings of Mucl expression.

On the other hand, at 18D, trachea showed Mucl expression. According to our results, trachea, along with stomach, kidney and lung was one of the more reactive tissues. During tracheal epithelial development, cells are undifferentiated at and before 17D, whereas at 18D, in coincidence with Mucl expression, a few large immature ciliated cells as well as secretory cells are observed. ${ }^{37,38}$ This result may also suggest that Mucl would be important in tracheal epithelia differentiation.

In mouse embryos and neonates, Braga et $a l^{20}$ analysed Mucl protein expression using CT1 anti-serum. They found Mucl expression in stomach, pancreas, lung, trachea, kidney and salivary glands which was also found in our analysis in rat embryos, but they did not find expression in small intestine and liver; we also detected Mucl reactivity in esophagus; this organ was not included in their series.

Considering all this information, we can conclude that Mucl could play a relevant role during epithelia cellular differentiation and proliferation.

Non-human studies related to MUC1 have been mainly developed to obtain animal models useful to the comprehension of cancer. In this sense, our results, developed in rat embryos, would provide information about MUC1 in relation to the biological interpretation of their expression profiles, in terms of tumor differentiation, cell lineage and dissemination.

To our knowledge, this is the first report about the pattern of expression of Mucl during rat embryogenesis.

\section{References}

1. Schock F, Perrimon N. Molecular mechanisms of epithelial morphogenesis. Annu Rev Cell Dev Biol 2002;18:463-93.

2. Gendler SJ. MUC1, the renaissance molecule. J Mammary Gland Biol Neoplasia 2001;6:339-53.

3. Burchell J, Wang D, Taylor-Papadimitriou J. Detection of the tumor-associated antigens recognized by the monoclonal anti- bodies HMFG-1 and 2 in serum from patients with breast cancer. Int J Cancer 1984;34:763-8.

4. Kufe D, Inghirami G, Abe M, Hayes D, Justi-Wheeler H, Schlom J. Differential reactivity of a novel monoclonal antibody (DF3) with human malignant versus benign breast tumors. Hybridoma 1984;3:223-32.

5. Patton S, Gendler SJ, Spicer AP. The epithelial mucin, MUC1, of milk, mammary gland and other tissues. Biochim Biophys Acta 1995;11241:407-23.

6. Croce MV, Colussi AG, Price MR, SegalEiras A. Expression of tumour associated antigens in normal, benign and malignant human mammary epithelial tissue: a comparative immunohistochemical study. Anticancer Res 1997;17:4287-92.

7. Croce MV, Isla-Larrain M, Rua CE, Rabassa ME, Gendler SJ, Segal-Eiras A. Patterns of MUC1 tissue expression defined by an anti-MUC1 cytoplasmic tail monoclonal antibody in breast cancer. J Histochem Cytochem 2003;51:781-8.

8. Duraisamy S, Ramasamy S, Kharbanda S, Kufe D. Distinct evolution of the human carcinoma-associated transmembrane mucins, MUC1, MUC4 AND MUC16. Gene 2006;373:28-34.

9. Lacunza E, Bara J, Segal-Eiras A, Croce MV. Expression of conserved mucin domains by epithelial tissues in various mammalian species. Res Vet Sci. 2009;86:68-77.

10. Parry S, Silverman HS, McDermott K, Willis A, Hollingsworth MA, Harris A. Identification of MUC1 proteolytic cleavage sites in vivo. Biochem Biophys Res Commun 2001;283:715-20.

11. Baeckström D, Hansson GC, Nilsson 0, Johansson C, Gendler SJ, Lindholm L. Purification and characterization of a membrane-bound and a secreted mucintype glycoprotein carrying the carcinomaassociated sialyl-Lea epitope on distinct core proteins. J Biol Chem 1991;266: 21537-47.

12. Spicer AP, Duhig T, Chilton BS, Gendler SJ. Analysis of mammalian MUC1 genes reveals potential functionally important domains. Mamm Genome 1995;6:885-8.

13. Taylor-Papadimitriou J, Burchell J, Miles DW, Dalziel M. MUC1 and cancer. Biochim Biophys Acta 1999;1455:301-13.

14. Takahashi T, Makiguchi Y, Hinoda Y, Kakiuchi H, Nakagawa N, Imai K, et al. Expression of MUC1 on myeloma cells and induction of HLA-unrestricted CTL against MUC1 from a multiple myeloma patient. J Immunol 1994;153:2102-9.

15. Brossart P, Schneider A, Dill P, Schammann T, Grünebach F, Wirths $S$, et al. The 
epithelial tumor antigen MUC1 is expressed in hematological malignancies and is recognized by MUC1-specific cytotoxic T-lymphocytes. Cancer Res 2001; 61:6846-50.

16. Croce MV, Isla-Larrain M, Remes-Lenicov F, Colussi AG, Lacunza E, Kim KC, et al. MUC1 cytoplasmic tail detection using CT33 polyclonal and CT2 monoclonal antibodies in breast and colorectal tissue. Histol Histopathol 2006;21:849-55.

17. Khodarev N, Ahmad R, Rajabi H, Pitroda S, Kufe T, McClary C, et al. Cooperativity of the MUC1 oncoprotein and STAT1 pathway in poor prognosis human breast cancer. Oncogene 2010;29:920-9.

18. Hollingsworth MA, Swanson BJ. Mucins in cancer: protection and control of the cell surface. Nat Rev Cancer 2004;4:45-60.

19. Singh PK, Behrens ME, Eggers JP, Cerny RL, Bailey JM, Shanmugam K, et al. Phosphorylation of MUC1 by Met modulates interaction with p53 and MMP1 expression. J Biol Chem 2008:283:2698595.

20. Braga VMM, Pemberton LF, Duhig T, Gendler SJ. Spatial and temporal expression of an epithelial mucin, Muc-1, during mouse development. Development 1992; 115:427-37.

21. Hudson MJ, Stamp GW, Chaudhary KS, Hewitt R, Stubbs AP, Abel PD, et al. Human MUC1 mucin: a potent glandular morphogen. J Pathol 2001;194:373-83.

22. Sun AP, Ohtsuki Y, Fujita J, Ishida T, Yoshinouchi T, Kohno N. KL-6, a human MU1 mucin, is expressed early in premature lung. Respir Med 2003;97:964-9.

23. Theiler K. The house mouse: Atlas of embryonic development. Springer Verlag, New York, USA, 1989.
24. Wilkinson MJ, Howell A, Harris M, TaylorPapadimitriou J, Swindell R, Sellwood RA. The prognostic significance of two epithelial membrane antigens expressed by human mammary carcinomas. Int $\mathbf{J}$ Cancer 1984;33:299-304.

25. Demichelis S, Alberdi C, Servi W, IslaLarrain M, Segal-Eiras A, Croce MV. Comparative immunohistochemical study of MUC1 and carbohydrate antigens in breast benign disease and normal mammary gland. Appl Immunohistochem Mol Morphol 2010;18:41-50.

26. Gendler SJ, Burchell JM, Duhig T, Lamport D, White R, Parker M, et al. Cloning of partial cDNA encoding differentiation and tumor-associated mucin glycoproteins expressed by human mammary epithelium. Proc Natl Acad Sci USA1987;84:60604.

27. Lan MS, Batra SK, Qi WN, Metzgar RS, Hollingsworth M. Cloning and sequencing of a human pancreatic tumor mucin cDNA. J Biol Chem 1990;265:15294-9.

28. Ball SM. The development of the terminal end bud in the prepubertal-pubertal mouse mammary gland. Anat Rec. 1998;250:45964.

29. Méio IB, Siviero I, Ferrante SM, Carvalho JJ. Morphologic study of embryonic development of rat duodenum through a computerized three-dimensional reconstruction: critical analysis of solid core theory. Pediatr Surg Int 2008;24:561-5.

30. Hisaoka M, Haratake J, Hashimoto H. Pancreatic morphogenesis and extracellular matrix organization during rat development. Differentiation 1993;53:163-72.

31. St-Pierre MV, Stallmach T, Freimoser Grundschober A, Dufour JF, Serrano MA, Marin JJ, et al. Temporal expression pro- files of organic anion transport proteins in placenta and fetal liver of the rat. Am J Physiol Regul Integr Comp Physiol 2004;287:R1505-16.

32. Hayashi Y, Toda K, Saibara T, Okamoto S, Osanai M, Enzan H, et al. Expression of fascin-1, an actin-bundling protein, in migrating hepatoblasts during rat liver development. Cell Tissue Res 2008;334: 219-26.

33. Yuan SF, Li KZ, Wang L, Dou KF, Yan Z, Han W, et al. Expression of MUC1 and its significance in hepatocellular and cholangiocarcinoma tissue. World J Gastroenterol 2005;11:4661-6.

34. Overturf K, al-Dhalimy M, Ou CN, Finegold M, Grompe M. Serial transplantation reveals the stem-cell-like regenerative potential of adult mouse hepatocytes. Am J Pathol 1997;151:1273-80.

35. Fiegel HC, Kluth J, Lioznov MV, Holzhüter S, Fehse B, Zander AR, et al. Hepatic lineages isolated from developing rat liver show different ways of maturation. Biochem Biophys Res Commun 2003;305: 46-53.

36. Crema VO, Fossati AC, Hamassaki DE, Santos MF. Distribution of small Rho GTPases in the developing rat submandibular gland. J Mol Histol 2008;39: 519-25.

37. Randell SH, Shimizu T, Bakewell W, Ramaekers FC, Nettesheim P. Phenotypic marker expression during fetal and neonatal differentiation of rat tracheal epithelial cells. Am J Respir Cell Mol Biol 1993;8:54655.

38. Qi BQ, Beasley SW. Stages of normal tracheo-bronchial development in rat embryos: resolution of a controversy. Dev Growth Differ 2000;42:145-53. 